\title{
Kahramanmaraş İlinde Bina İçi Mevsimsel Radon Gazı Aktivitesi Ölçümü
}

\author{
Erdal KÜÇÜKÖNDER*
}

\author{
Kahramanmaraş Sütçü Imam Üniversitesi, Teknik Bilimler MYO, Malzeme ve Malzeme Işsleme Teknolojileri \\ Bölümü, Kahramanmaraş, Türkiye \\ (ORCID: 0000-0001-9661-1583)
}

\begin{abstract}
$\ddot{\mathbf{O z}}$
Radon gazı $\left({ }^{222} \mathrm{Rn}\right) ;{ }^{238} \mathrm{U}$ doğal radyoaktif serisinde bulunan kokusuz, tatsız ve renksiz bir gazdır. ${ }^{226} \mathrm{Ra}$ 'nın kız çekirdeği olan ${ }^{222} \mathrm{Rn}, 5.490 \mathrm{MeV}$ enerjili alfa parçacıkları yayımlayarak bozunur. Alfa parçacıkları en yüksek iyonlaştırmaya sahip parçacıklar olduğu için radon gazının solunması ciddi akciğer hastalıklarına neden olabilir. Günlük hayatımızda maruz kaldığımız radyasyon dozunun \%54'ünün özellikle ${ }^{222}$ Rn'den kaynaklandığ bilinmektedir. Dünya Sağlık Örgütü'ne (WHO) ve ABD Çevre Koruma Ajansı'na (EPA) göre; radon gazı, sigaradan sonra akciğer kanserinin ikinci önde gelen sebebidir. Bu çalışmada Kahramanmaraş Sütçü İmam Üniversitesi (KSÜ), Avşar Yerleşkesi'nde bulunan tüm binalarda bina içi, mevsimsel olarak radon gazı aktivitesi DURRIDGE Rad7 elektronik radon dedektörü kullanılarak ölçüldü. Bu çalışmada amaç, tüm çalışanlar ve öğrencilerin sağlık açısından ne kadar risk altında olduğunu tespit etmektir. Bina içi kışlık radon konsantrasyon değerleri 8, $52 \pm 3,24 \mathrm{~Bq} \mathrm{~m}^{-3}$ ile 53,12 $\pm 16,46 \mathrm{~Bq} \mathrm{~m}^{-3}$ arasındadır. Yazlık radon konsantrasyon değerleri 4,74 $\pm 1,34$ $\mathrm{Bq} \mathrm{m}^{-3}$ ile 22,79 $\pm 9,28 \mathrm{~Bq} \mathrm{~m}^{-3}$ arasındadır. Bu değerler tavsiye edilen sınır değerlerin altındadır.
\end{abstract}

Anahtar kelimeler: Radon gazı, Bina içi radon gazı ölçümü, DURRIDGE Rad7.

\section{Seasonal Indoor Radon Gas Activity Measurement in Kahramanmaraş Province}

\begin{abstract}
Radon gas $\left({ }^{222} \mathrm{Rn}\right)$; It is an odorless, tasteless and colorless gas in the natural radioactive series ${ }^{238} \mathrm{U}$. Radon gas is the daughter core of ${ }^{226} \mathrm{Ra} .{ }^{222} \mathrm{Rn}$ decays by emitting alpha particles with an energy of $5.490 \mathrm{MeV}$. Since alpha particles are the particles with the highest ionization, inhalation of radon gas can cause serious lung disease. It is known that $54 \%$ of the radiation dose we are exposed to in our daily lives is caused by ${ }^{222} \mathrm{Rn}$. According to World Health Organization (WHO) and the US Environmental Protection Agency (EPA), Radon is the second leading cause of lung cancer after smoking. In this study, seasonal Radon gas activity in all buildings in Kahramanmaraş Sütçü İmam University (KSÜ) Avşar campus was measured using DURRIDGE Rad7 electronic radon detector. The purpose of this study is to observe the health risk of all employees and students. The winter radon concentration in indoor samples varies from $8.52 \pm 3.24 \mathrm{~Bq} \mathrm{~m}^{-3}$ to $53.12 \pm 16.46 \mathrm{~Bq} \mathrm{~m}^{-3}$. The summer radon concentration in indoor samples varies from $4.74 \pm 1.34 \mathrm{~Bq} \mathrm{~m}^{-3}$ to $22.79 \pm 9.28 \mathrm{~Bq} \mathrm{~m}^{-3}$. These values were found to be below the recommended limit values.
\end{abstract}

Keywords: Radon gas, Indoor radon gas measurement, DURRIDGE Rad7.

\section{Giriş}

Günlük hayatımızda sürekli bir radyasyonun etkisinde kalmaktayız. Radyoaktif çekirdekler kararsız haldedirler. Kararlı hale dönebilmek için enerji yayımlarlar. Yayımladıkları bu enerji radyasyon olarak tanımlanmış olup, 1896 yılında Henri Becquerel bu konuda çalışmalar başlatmıştır. Radyasyon, yayımlandığı kaynak bakımından yapay radyasyon ve doğal radyasyon olmak üzere ikiye ayrılır. Ayrıca hücrelerde iyonizasyona sebep olanlarına, iyonlaştırıcı radyasyon, iyonizasyona sebep olmayana ise iyonlaştırıcı olmayan radyasyon denir. Genelde doğal kaynaklardan ortaya çıkan iyonlaştırıcı

*Sorumlu yazar: erdalkucukonder@gmail.com

Geliş Tarihi: 28.05.2021, Kabul Tarihi: 12.08.2021 
radyasyon, maddeyle etkileşerek atomlarının elektriksel yapısını değiştirebilir, dolayısıyla sağlık sorunlarına sebep olabilir. Çevremizde sürekli var olan doğal radyasyonun yaklaşı \% 054 'ünün gözle görünmeyen ve duyular vasitasıyla algılanamayan renksiz, tatsız, kokusuz bir gaz olan radon gazı ve onun kısa yarı ömürlü kız çekirdeklerinden oluştuğu bildirilmiştir [1,2]. Radon gazı, solunum sistemine girdikten sonra çok hızlı bir bozunma mekanizması ile $\alpha$ ve $\beta$ radyasyonu yayar ve bu bozunma mekanizması ayrıca akciğer kanserine yol açan toksik bir radyoizotop olan ${ }^{210} \mathrm{Po}$ yu da içerir [3].

Yeryüzünde yaşayan tüm canlılar, yerkürenin oluşumundan bu yana yerkürede bulunan doğal radyoaktif maddelerden yayımlanan radyasyonla ve aynı zamanda uzaydan gelen kozmik 1şınlarla ışınlanmaktadır. Tüm canlıların yaşamları boyunca, Dünya'da yerküreden kaynaklanan, doğal radyasyona maruz kaldıkları bildirilmiştir [4-10]. Tüm canlılar vücutlarına, hava solurken solunum yolu ile, beslenirken sindirim yolu ile havada ve yiyeceklerde bulunan radyoaktif maddeleri almaktadır. Alınan bu radyoaktif maddeler ilgili organlarda birikerek iç ışınlanmaya sebep olmaktadır. Buna ek olarak yerküredeki doğal radyoaktif maddelerden ve kozmik ışılardan etkilendiğimiz de düşünüldüğünde, tüm canlılar hem iç hem de dış radyasyona doğal olarak maruz kalmaktadır [11].

${ }^{238} \mathrm{U},{ }^{232} \mathrm{Th}$ serileri ve ${ }^{40} \mathrm{~K}$ oldukça fazla süre yarı ömre sahip olup, topraklarda, sularda, havada bulunmakta, canlıları dıştan ve içten 1 şınlamaktadırlar. Radon gazı, ${ }^{238} \mathrm{U}$ serisinde bulunan kız çekirdeklerden 1600 yıl yarı ömre sahip ${ }^{226} \mathrm{Ra}$ 'nın bozunması ile ortaya çıkar. Yine aynı seride bulunan 22,6 y1l yarı ömre sahip ${ }^{210} \mathrm{~Pb}$ ise bu zinciri etkin bir şekilde korur. Radon gazının yarı ömrü 3,8 gün olup radyoaktif bir asal gazdır. Buna karşılık bu radyoaktif seride radondan sonra gelen ${ }^{218} \mathrm{Po},{ }^{214} \mathrm{~Pb}$, ${ }^{214} \mathrm{Bi}$ ve ${ }^{214} \mathrm{Po}$ kız çekirdekler, radon gazı gibi pasif olmayıp alfa ve beta yayımlayan, kimyaca aktif katı elementlerdir. Radon gazı alfa yayımladığı için, alfa ışınının giriciliği çok az olduğundan dış ışınlama tehlikesi yoktur. Radon gazının uzun süre solunması, akciğerler için önemli bir sağlık riski oluşturabilmektedir. Radon gazının bozunma ürünlerinin, genellikle akciğer mukozasına yerleşerek akciğer kanseri riskini artırdığı bilinmektedir [12]. WHO ve EPA radonu, A sınıfı kanserojen madde olarak sınıflandırmıştır [13]. İngiltere Milli Radyasyondan Korunma Komitesi (NRPB), İngiltere'de bir yılda meydana gelen 41000 akciğer kanseri vakasının en az 2500'ünün radon gazına bağlı olduğu bildirmektedir [14].

Yer altı maden ocaklarında çalışan işçiler maden ocağı havasında bulunan radyonüklidleri solumaları ve yutmaları sebebi ile sağlık açısından mesleki risk altındadırlar. Maden işçileri hem havadaki radon gazı ve onun kız çekirdekleri hem de jeolojik yapıda bulunan doğal radyoaktif elementlerden yayımlanan gama radyasyonu ile içten ve dıştan ışına maruz kalmaktadırlar. Epidemiolojik çalışmalar, uzun süre radyasyona maruz kalmanın akciğer kanseri riskini artırdığını göstermektedir [15]. Radon gazı, solunması sonucu akciğerlerde alfa yayımlaması sebebi ile hassas hücrelerde iyonizasyona sebep olduğu için akciğer kanseri riskini artırdığı yönünde çok sayıda bulgunun varlığı nedeni ile birçok ülkede araştırmacıların ilgisini çekmiş olup, bu konuda hem ülkemizde hem de diğer ülkelerde çalışmalar yapılmıştır [16-18].

İnsanlar, günlük yaşantısının yaklaşık \%90' ını kapalı ortamlarda geçirmektedirler $[19,20]$. Bina içi kapalı ortamlarda, bina temeli altında bulunan kayaç ve toprak sebebi ile radon gazı bulunmaktadır. Radon gazı yeraltından yükselerek binanın altından düşük basınçlı bina içerisine, duvar ve zemin çatlaklarından, su borusu boşluklarından v.b. girerek katlar arasında yükselerek kapalı mekânları doldurur.

Radon gazı doğrudan ve onun kız çekirdekleri havadaki asılı bulunan toz ve diğer parçacıklara tutunur ve böylece radyoaktif aerosol oluşturur. Solunarak akciğerlere alınan bu radyoaktif maddeler kararlı duruma gelinceye kadar radyoaktif ışın yayımlayarak akciğerlerde iyonizasyona sebep olurlar. Son ürün olarak kararlı kurşuna dönüşünce de akciğerlerde hassas hücreler üzerinde ağır element birikimi de hücrelere zarar verebilir ve akciğer kanserine neden olabilir. Uranyum madencileri üzerinde yapılan araştırmaların, radon gazının akciğer kanseri için ana sebep olduğunu ortaya koymasıyla, radon gazına maruz kalma sınırlandırılmıştır. Bina içi radon gazı ölçümleri bu çerçevede oldukça önem kazanmıştır. Çünkü canlıların, doğal kaynaklar sebebi ile maruz kaldıkları toplam radyasyon dozunun \%54'ünün radon gazı sebebi ile olduğu bildirilmiştir [17].

Bina içi radon gazı konsantrasyonları, aktif veya pasif ölçme metotları için dizayn edilmiş ölçüm cihazları ile belirlenebilmektedir. Dünya genelinde ve ülkemizde literatürde kapalı ortam (meskenlerde, mağaralarda, madenlerde, termik santrallerde ve kütüphanelerde) radon gazı konsantrasyonu ölçme konusunda yapılan çalışmalar oldukça fazladır [21-32]. ABD'de ve Avrupa ülkelerinde bu ölçümler 
sürekli tekrarlanarak yapılmakta ve radyasyon haritaları güncellenmektedir. ABD' de bir yılda 1 milyon radon gazı yoğunluğu ölçümü yapıldığı bildirilmiştir [33].

Uluslararası Atom Enerji Ajans1, temel güvenlik standartları (IAEA-BSS), tavsiye edilen radon gazı konsantrasyon seviyesini evlerde $200-600 \mathrm{~Bq} \mathrm{~m}^{-3}$, işyerlerinde $500-1500 \mathrm{~Bq} \mathrm{~m}^{-3}$ olarak, Türkiye Atom Enerji Kurumu (TAEK) Radyasyon Güvenliği Yönetmeliğinde ise, ülkemiz için müsaade edilen radon gazı konsantrasyonu, evler için $400 \mathrm{~Bq} \mathrm{~m}^{-3}$, işyerleri için $1000 \mathrm{~Bq} \mathrm{~m}{ }^{-3}$ olarak belirlenmiştir. Uluslararası Radyolojik Koruma Komisyonu tarafindan radon gazı konsantrasyonu için tavsiye edilen değerler ise, evler için y1llık 200-600 Bq m${ }^{-3}$ dür. Aynı Komisyonun evlerde radon gazı konsantrasyonları için belirlediği sınırlar; yeni evlerde $200 \mathrm{~Bq} \mathrm{~m}^{-3}$, eski evlerde $400 \mathrm{~Bq} \mathrm{~m}^{-3}$ ve maden bölgelerinde ise $1500 \mathrm{~Bq} \mathrm{~m}^{-3}$ dür. $400 \mathrm{~Bq} \mathrm{~m}^{-3}$, lük sinır değerde ise akciğer kanseri meydana gelme riski \%6'dır. Bu risk değeri, sigara kullanımı ile 10-20 kat kadar artabilmektedir [34,35].

Kahramanmaraş'ta bazı ilköğretim okullarında ve anaokullarında radon gazı seviyesi pasif radon dedektör kullanılarak [36], faylarla ilişkili jeotermal alanlarda aktif ölçer kullanılarak ölçülmüştür [37]. Kahramanmaraş Sütçü İmam Üniversitesi Avşar Yerleşkesi'nde daha önce radon gazı ölçümü ile ilgili bir çalışma yapılmamıştır.

Bu çalışmamızın amacı Kahramanmaraş Sütçü İmam Üniversitesi Avşar Yerleşkesi'nde 12 binada radon gazı ölçümü yaparak, çalışanlar ve öğrenciler için sağlık risklerini değerlendirmek ve gerekli tedbirlerin alınmasını sağlamaktır.

\section{Materyal ve Metot}

\subsection{Calıșma Alanı}

Kahramanmaraş ilimiz Akdeniz Bölgesi'nin doğusundadır. İklim merkez ilçelerde Akdeniz Bölgesi'ne yakın iklime sahiptir. Kahramanmaraş Sütçü İmam Üniversitesi şehrimizin güneybatısında Onikişubat ilçesindedir. Kahramanmaraş Sütçü İmam Üniversitesi Avşar Yerleşkesi'nde fakülte ve idari birimler olmak üzere toplam 12 binada ölçümler yapılmıştır. Bu binalarda, hizmet veren yaklaşık 2.000 akademik ve idari personel ile eğitim gören 20.000 öğrenci bulunmaktadır. Kahramanmaraş ilinin ülkemizdeki yeri Şekil 1' de ve Kahramanmaraş Sütçü İmam Üniversitesi Avşar Yerleşkesi'nin konumu Şekil 2' de verildiği gibidir.

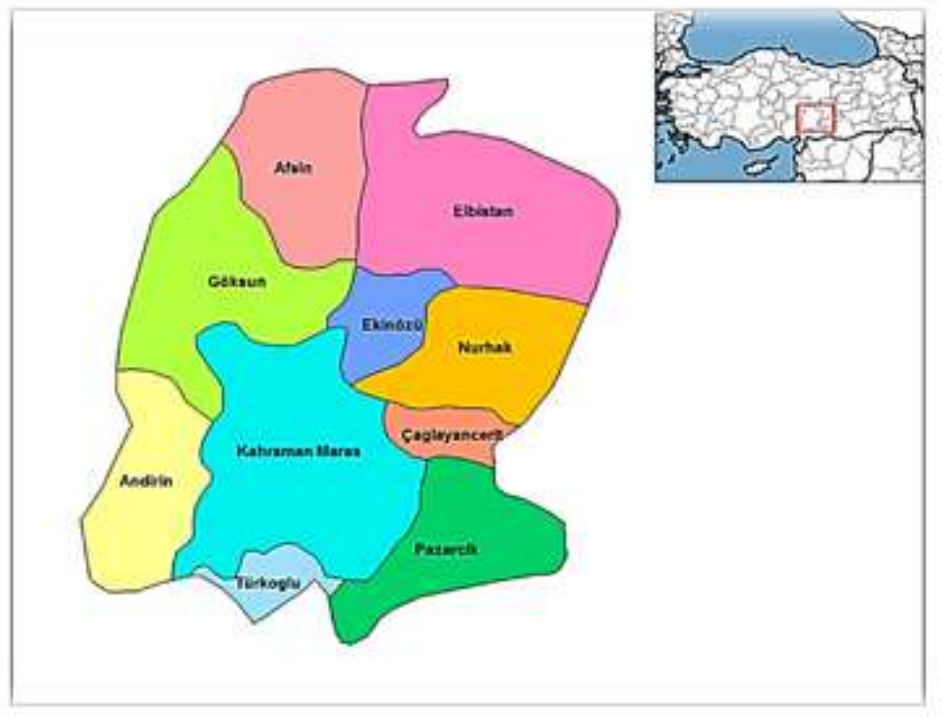

Şekil 1. Kahramanmaraş, Türkiye [38] 


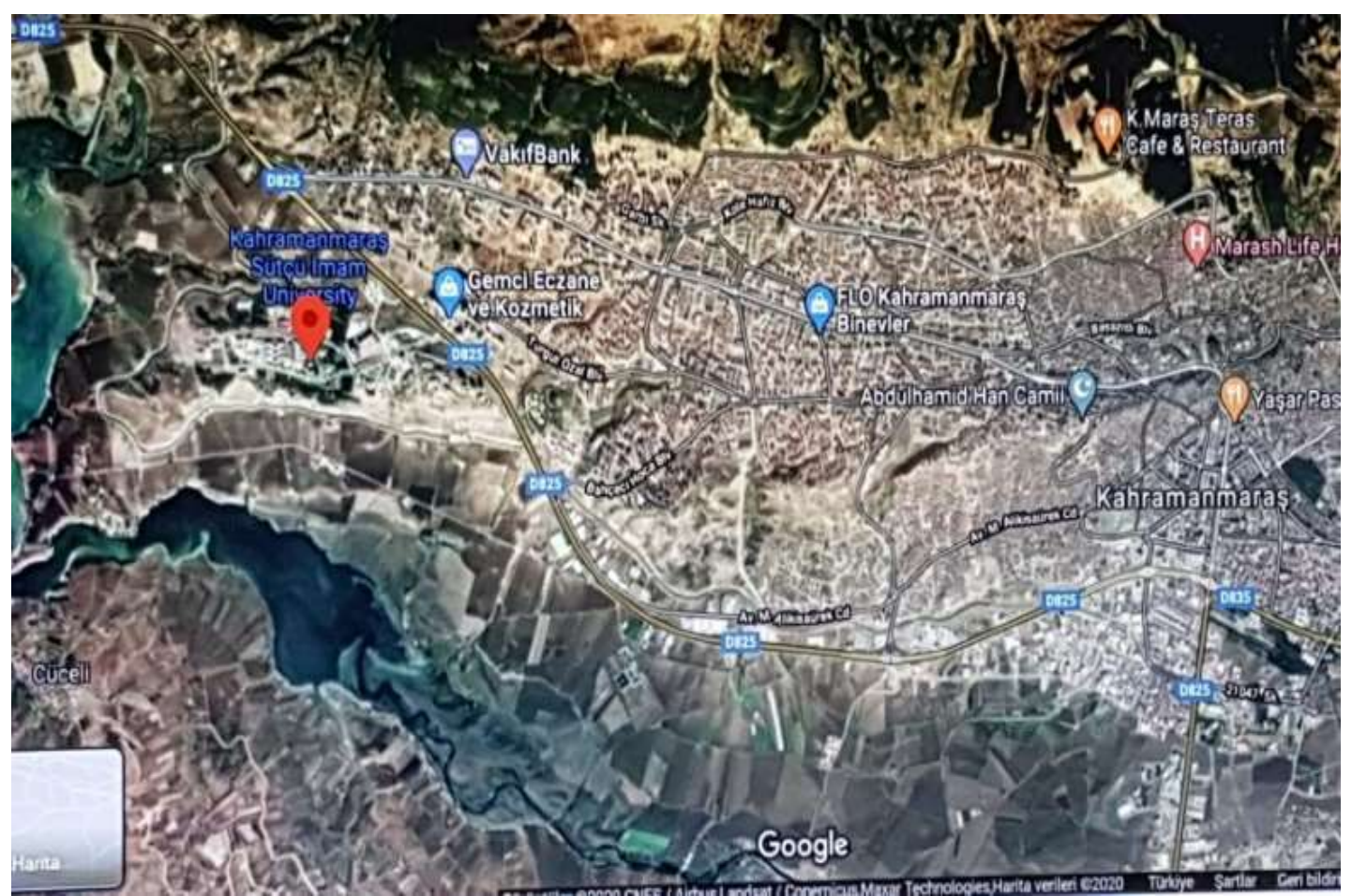

Şekil 2. Kahramanmaraş merkezde KSU Avşar Yerleşkesi'nin konumu

\subsection{Deneysel Çalışma}

Kahramanmaraş ilinde, Kahramanmaraş Sütçü İmam Üniversitesi Avşar Yerleşkesi’nde bina içi radon gazı ölçümleri, Yerleşke'deki on iki binada yapıldı.

Binanın oturduğu zemindeki toprak ve kayalar, bina içi radon gazı yoğunluğunun ana sebebidir. Yer altından gelen radon gazı yukarı doğru yükselir ve bina tabanında bir basınç oluşturur. Kış aylarında binanın etrafında bulunan alanlarda yağış nedeni ile gözeneklerin kapanması ve bina içi sıcaklığın artması ile içeride basınç azalması olacağından, radon gazı daha hızlı bir şekilde bina içine girer. Kışın havaların soğuk olması sebebi ile havalandırma da az olduğundan radon gazı seviyesi bina içinde yüksek olur. Yazın ise, bina dışı ortamda toprak çatlaklarının artması ve havalandırmanın daha fazla olması sebebi ile durum tam tersine döner, bina içi radon gazı yoğunluğu azalır. Ayrıca, bulunulan bölgedeki toprak ve kayaçlar ile birlikte yapı malzemeleri içerisinde bulunan ${ }^{226} \mathrm{Ra}$ yoğunluğu da radon gazı miktarını etkiler.

Radon gazı bina içine; bina zemininde bulunan çatlaklardan, duvarlardaki çatlaklardan, çeşitli tesisat boşluklarından, yapının bağlantı noktaları vb. yerlerden girmekle birlikte, kum, çimento, boya, kireç, alçı gibi yapı malzemelerinden de girer. Bunların yanında içme-kullanım suları ve doğal gazda bulunan radon gazının da bina içinde radon gazı yoğunluğunu artırabildiği bildirilmiştir [39].

Yapı malzemelerinin de radon gazı konsantrasyonuna etkisinin olduğu bilinmektedir. Örneğin, duvarları taş ve tuğla olan binalara göre, briket olan binaların radon gazı konsantrasyonları daha yüksektir. Ayrıca tavanı beton olan evlere göre, tavanı toprak olan evlerin radon gazı konsantrasyonlarının daha fazla olduğu bildirilmiştir [40].

Şekil 3’te radon gazının binalara nerelerden girdiği gösterilmektedir: 1) Duvar içi kaviteleri, 2) Zemindeki çatlaklar, 3) Yapı birleşim noktaları, 4) Duvarda meydana gelen çatlaklar, 5) Binaya giren su kaynakları, 6) Asma tavan boşluğu, 7) Boru çevresi boşluğu [41]. 


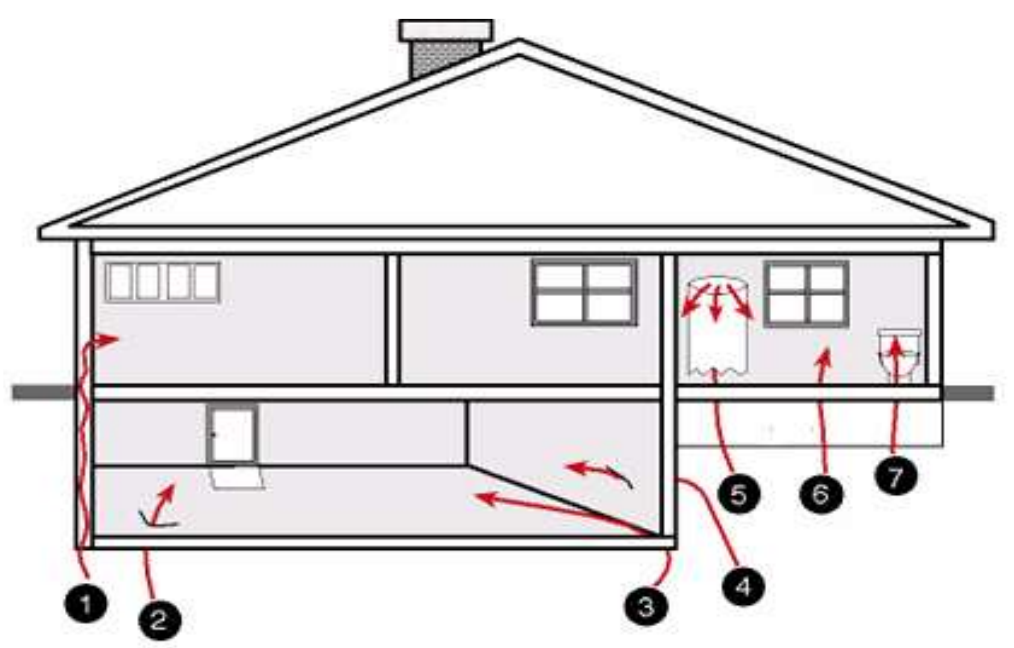

Şekil 3. Radon'un binalara giriş noktaları [41]

\subsection{Durridge RAD7 Elektronik Radon Dedektörü Algılayıcısı ve Yapısı}

Dedektör 4,3 kg ağırlığında olup bataryası sayesinde sniff modunda 24 saat, monitör modunda ise 72 saat ölçümler yapabilir. Ayrıca laboratuvar ortamında doğrudan adaptör ile de prize takılarak ölçüm yapılabilir. Şekil 4'te ve Şekil 5'te DURRIDGE Rad7 elektronik radon dedektörü görülmektedir.

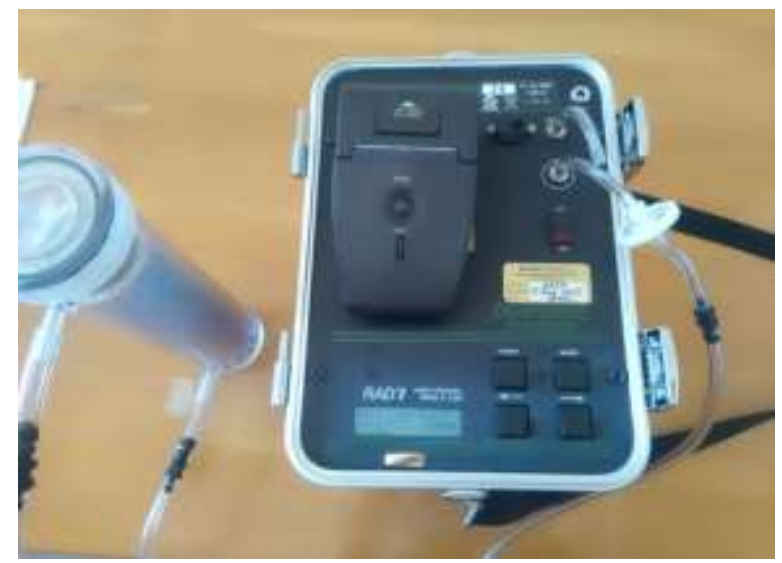

Şekil 4. DURRIDGE Rad7 elektronik radon dedektörü

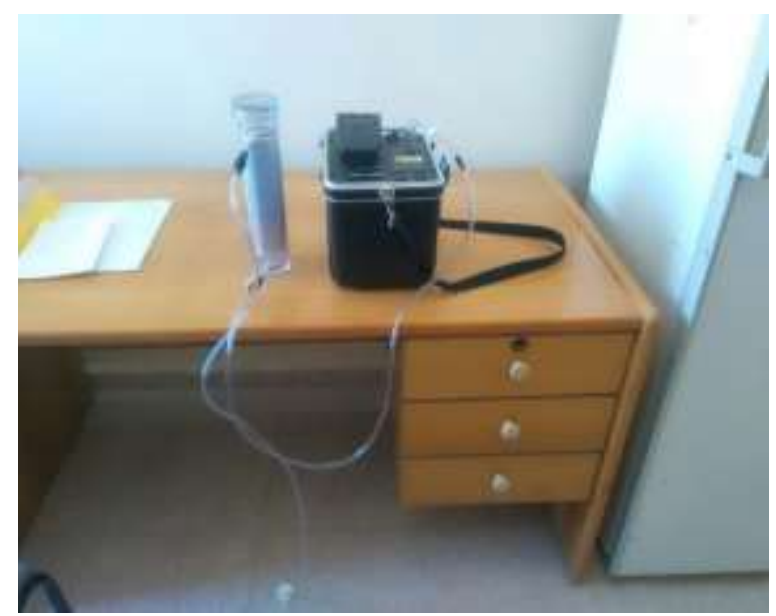

Şekil 5. DURRIDGE Rad7 elektronik radon dedektörü 
DURRIDGE Rad7 elektronik radon dedektörü; portatif, taşınabilir olup, bataryası sayesinde herhangi bir güç kaynağına bağlı kalmaksızın her mekânda ölçüm yapabilir ve verileri depolayabilir. Yapılan ölçümlerin tamamını, üzerinde bulunan yazıcı ile her ölçüm sonrası çıtı olarak verebilirken yapılan ölçüm bilgileri sistem bilgisayara bağlanarak bilgisayara aktarılabilir. Depolanan ölçüm verilerinin, bilimsel olarak yorumunu yapabilmek için veri analiz yazılım ile birlikte çalışır. Ayrıca yerinde aktif ölçümler yapılmasında kullanılan DURRIDGE Rad7 elektronik radon dedektörü bilgisayara bağlanarak ölçüm sırasındaki değişimler gözlenebilmektedir.

Rad7, kapsamlı bir radon ölçümünün temelini oluşturabilen çok yönlü bir cihazdır. Farklı amaçlar için birçok farklı modda kullanılabilir. Rad7, sinyal ve gürültü arasında net bir şekilde ayrım yapmak için gelişmiş bir silikon dedektörü ve yüksek çözünürlüklü alfa spektroskopisi ile elektrostatik çökeltme kullanır. Bu nedenle, darbe iyonizasyon odaları kullanan radon monitörlerinin aksine Rad7, radon ve toron arasında kolayca ayrım yapar ve cihazın ömrü boyunca arka planı düşük kalır. $\mathrm{Bu}$ yöntemi tercih etmemizin sebebi ise, radon gazının anlık ölçümü için kullanılan yöntemlerde, bozunma sonrası ortaya çıkan alfa parçacığının, dedeksiyonunun çok kısa bir zamanda içerisinde olmasına dayanmaktadır. Genellikle bu yöntemde Lucas hücresi kullanılır. İntegral ölçüm yönteminde radon gazının, bir süre zarfında toplanması ile ölçümler yapılır. Bu sebep ile, ölçüm için 10 gün ile 180 gün arasında değişen uzun zaman aralığına ihtiyaç vardır. Bu da, yöntem için kısa süreli bilgilere ulaşmada dezavantaj olmaktadır. Bu yöntemde pasif iz dedektörleri kullanılır. Sürekli radon ölçümlerinde ise aktif elektronik dedektörler kullanılır. Aktif dedektörler, sürekli ölçümlerde 10 dakika gibi periyotlarla ara vermeksizin ölçümler yapılır ve yapılan ölçümler sisteme kayıt edilebilir. Bunun için üretilmiş çok sayıda elektronik cihaz vardır. Bunlardan birisi de Durrige Rad7 ölçüm cihazıdır.

Bina içi yapılan çalışmalarda; daha önceden belirlenen bina içi radon gazı ortalamalarını en iyi şekilde temsil edebilecek odalar tercih edildi. DURRIDGE Rad7 elektronik radon dedektörü ile önceden belirlenen odalarda zeminde ve zeminin $1 \mathrm{~m}$ üzerinde koklama modunda ölçümler gerçekleştirildi. Farklı yüksekliklerde ölçmemin sebebi radon gazının, hidrojenden 100 kat ve havadan ise yedi buçuk kat kadar daha ağır olmasından dolayıdır [42]. Bu işlem binaların her katında kapalı kalmış odalarda kış mevsiminde 14.01.2016-25.02.2016 tarihleri arasında ve yaz mevsiminde 19.07.2016-01.09.2016 tarihleri arasında sabah 08:00 ile 17:00 saatleri arasında yapıldı. Yapılan ölçüm Şekil 6' da gösterildiği gibidir.

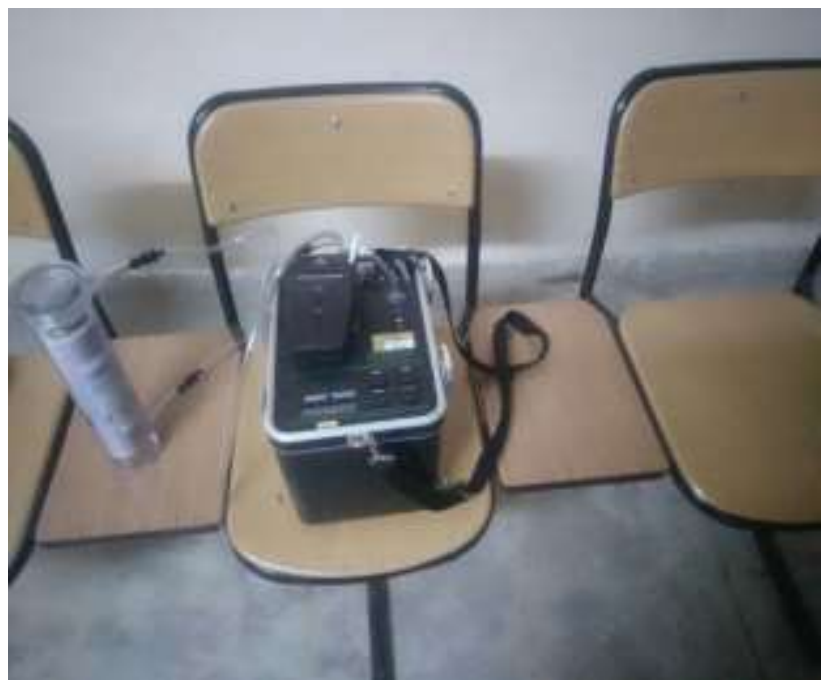

Şekil 6. DURRIDGE Rad7 elektronik radon dedektörü ile bina içinde yapılan ölçüm

$\mathrm{Bu}$ çalışmada elde edilen değerler için, tüm binalarda belirlenen her istasyonda ve her iki yükseklikte ayrı ayrı 15'er dakikalık periyotlar ile üçer defa ölçüm yapılmıştır. Her iki yükseklik için yapılan üçer ölçümün aritmetik ortalamaları alınarak ortalama değerler bulunmuştur ve standart sapmaları hesaplanmıştır. Standart sapmaları hesaplanan bu ortalama değerler Tablo 1 ve Tablo 2' de sunulmaktadir. 


\section{Bulgular ve Tartışma}

Bu çalışmada, Kahramanmaraş Sütçü İmam Üniversitesi, Avşar Yerleşkesi'nde tüm binalarda yer altından gelen ve yapı malzemelerinden yayımlanan, bina içi radon konsantrasyonlarının mevsimsel değişimi DURRIDGE Rad7 elektronik radon dedektörü ile yapıldı.

Tablo 1'de 14.01.2016-25.02.2016 tarihleri arasındaki bina içi radon ortalamaları ve Tablo 2'de 19.07.2016-01.09.2016 tarihleri arasındaki bina içi radon ortalamaları verilmektedir.

Tablo 1. 14.01.2016-25.02.2016 tarihleri arasındaki radon ortalamaları

\begin{tabular}{ccc}
\hline Binalar & $\begin{array}{c}\text { Zemin } \\
\left(\mathrm{Bq} \mathrm{m}^{-3}\right)\end{array}$ & $\begin{array}{c}\text { Zeminin 1 m üzeri } \\
\left(\mathrm{Bq} \mathrm{m}^{-3}\right)\end{array}$ \\
\hline Eğitim Fakültesi & $36.37 \pm 12.18$ & $27.32 \pm 11.70$ \\
Fen-Edb.Fak. & $36.32 \pm 13.64$ & $24.72 \pm 10.66$ \\
İlahiyat Fakültesi & $28.48 \pm 11.64$ & $19.92 \pm 8.38$ \\
Orman Fakültesi & $21.16 \pm 10.56$ & $19.52 \pm 8.74$ \\
Yabancı Diller Yüksek & $22.77 \pm 10.88$ & $18.68 \pm 8.42$ \\
Okulu & $38.66 \pm 14.80$ & $29.40 \pm 12.36$ \\
Ziraat Fakültesi & $28.78 \pm 12.64$ & $20.89 \pm 11.74$ \\
İİ̈F & $11.36 \pm 4.36$ & $8.52 \pm 3.24$ \\
Rektörlük & $38.01 \pm 13.72$ & $21.38 \pm 9.68$ \\
Kütüphane & $53.12 \pm 16.46$ & $45.19 \pm 14.76$ \\
Ö̆ğrenci İşleri Daire Bşk. & $28.48 \pm 11.24$ & $17.06 \pm 6.74$ \\
Görsel Sanatlar & $27.30 \pm 11.66$ & $22.63 \pm 10.34$ \\
Kafeterya & &
\end{tabular}

Tablo 2. 19.07.2016-01.08.2016 tarihleri arasındaki radon ortalamaları

\begin{tabular}{ccc}
\hline Binalar & $\begin{array}{c}\text { Zemin } \\
\left(\mathrm{Bq} \mathrm{m}^{-3}\right)\end{array}$ & $\begin{array}{c}\text { Zeminin 1 m üzeri } \\
\left(\mathrm{Bq} \mathrm{m}^{-3}\right)\end{array}$ \\
\hline Eğitim Fakültesi & $20.48 \pm 9.34$ & $17.37 \pm 4.26$ \\
Fen-Edb.Fak. & $22.79 \pm 9.28$ & $21.54 \pm 9.64$ \\
İlahiyat Fakültesi & $11.42 \pm 4.56$ & $8.7 \pm 3.34$ \\
Orman Fakültesi & $6.52 \pm 2.66$ & $5.97 \pm 2.44$ \\
Yabanci Diller Yüksek Okulu & $14.25 \pm 5.70$ & $11.36 \pm 4.64$ \\
Ziraat Fakültesi & $16.12 \pm 5.32$ & $12.58 \pm 3.26$ \\
İİBF & $6.63 \pm 2.70$ & $4.74 \pm 1.34$ \\
Rektörlük & $9.68 \pm 3.64$ & $7.27 \pm 3.36$ \\
Kütüphane & $14.24 \pm 5.40$ & $11.38 \pm 4.34$ \\
Öğrenci İşleri Daire Bşk. & $15.17 \pm 4.42$ & $12.57 \pm 3.50$ \\
Görsel Sanatlar & $11.42 \pm 3.68$ & $10.40 \pm 3.38$ \\
Kafeterya & $22.61 \pm 10.44$ & $17.96 \pm 4.62$ \\
\hline
\end{tabular}

Tablo 3. Ev ve iş yerleri için ulusal ve uluslararası kuruluşlarca belirlenen radon gazı limitleri [43]

\begin{tabular}{lcc}
\hline \multicolumn{1}{c}{ Kuruluşlar } & \multicolumn{2}{c}{ Önerilen limitler $\left(\mathrm{Bq} \mathrm{m}^{-3}\right)$} \\
& Ev & İş yeri \\
\hline ICRP & $\leq 300$ & $\leq 1000$ \\
WHO & $\leq 100$ & \\
AB & $\leq 300$ & $\leq 1000$ \\
TAEK & $\leq 400$ & $\leq 1000$ \\
\hline
\end{tabular}

Bina içi kışlık radon konsantrasyon değerleri zeminde $11,36 \pm 4,36 \mathrm{~Bq} \mathrm{~m}^{-3}$ ile $53,12 \pm 16,46 \mathrm{~Bq} \mathrm{~m}^{-3}$ arasında değişmekte olup zeminin $1 \mathrm{~m}$ üzerinde ise $8,52 \pm 3,24 \mathrm{~Bq} \mathrm{~m}^{-3}$ ile $45,19 \pm 14,76 \mathrm{~Bq} \mathrm{~m}^{-3}$ arasında 
değişmektedir. En yüksek kışlık radon konsantrasyonu zeminde Öğrenci İşleri Daire Başkanlığında, zeminin $1 \mathrm{~m}$ üzerinde ise yine Öğrenci İşleri Daire Başkanlığında ölçüldü. Bina içi yazlık radon konsantrasyon değerleri zeminde $6,52 \pm 2,66 \mathrm{~Bq} \mathrm{~m}^{-3}$ ile $22,79 \pm 9,28 \mathrm{~Bq} \mathrm{~m}^{-3}$ arasında değişmekte olup

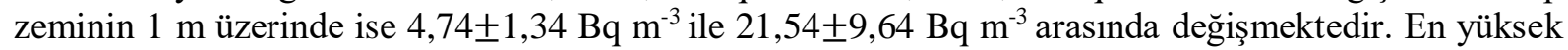
yazlık radon konsantrasyonu zeminde Fen-Edebiyat Fakültesi binasında, zeminin $1 \mathrm{~m}$ üzerinde ise yine Fen- Edebiyat Fakültesi binasında ölçüldü. Hem Öğrenci İşleri Daire Başkanlığı hem de Fen-Edebiyat Fakültesi binası Yerleşke'nin en eski binalarından olup 17 yıl önce yapımı tamamlanmıştır. Binanın yaşının yüksek olması zemin çatlakları ve atık su boru boşluklarının daha fazla olmasına neden olabilir. Bu nedenle de diğer binalara göre, radon gazı değerleri daha yüksek olabilir. Ayrıca, Öğrenci İşleri Daire Başkanlığı binasında merkezi iklimlendirme sisteminin bulunması sebebiyle yaz aylarında odaların havalandırması iyi yapılmamış olabilir. Ölçüm yapılan binalarda, insan sağlığı için Tablo 3 'te verilen ICRP, WHO, AB ve TAEK tarafindan belirlenen limit değerler ile karşılaştırma yapıldı. Ölçüm yapılan binalarda ölçüm sonuçlarının tümü ulusal ve uluslararası kurum ve kuruluşlar tarafindan tanımlanan limit değerlerinin altındadır. Yapılan ölçümlerin tamamı önerilen seviyelerden düşüktür.

Binalar arasındaki farklılıklar, binaların bulunduğu zemin ile arasındaki izolasyon farkı, zeminde bulunan çatlak ve atık su tesisatı boşluk farklılıkları ve binalarda kullanılan inşaat malzeme farklılıklarından olabilir. Kışın yapılan ölçüm değerleri yaz değerlerine göre yüksektir. Bunun nedeni kış aylarında yağış nedeni ile bina dışı toprağın, gözenek ve çatlaklarının kapalı olması ve binanın altında kalan toprağın kuru kalması sebebi ile oluşan yüksek basınçla radon gazının bina içine girmesi ve kış aylarında havalandırma eksikliklerinden olabilir. Ayrıca zeminde yapılan ölçümlerin, zeminin 1 m üzerine yapılan ölçümlerden yüksek çıkması radon gazının havadan ağır olmasındandır.

Tüm bunlara ilave olarak, Kahramanmaraş il merkezinde faaliyet gösteren 16 farklı ilköğretim ve anaokullarında 28.08.2013-01.11.2013 tarihleri arasında yapılan ölçümlerde ortalama radon konsantrasyonu 52,25 $\mathrm{Bq} \mathrm{m}^{-3}$ ve 01.11.2013-03.01.2014 tarihleri arasında yapılan ölçümlerde ortalama radon konsantrasyonu $67,30 \mathrm{~Bq} \mathrm{~m}^{-3}$ olarak ölçülmüştür [36]. Bu ölçümlerde CR-39 pasif iz dedektörü kullanılmıştır. Bizim çalışmamıza göre ortalama değerler yüksektir, bunun sebebi ölçüm yapılan okulların bulunduğu zeminin kayaç ve toprak yapılarının farklı olması, havalandırma alışkanlıkları ile birlikte bina yaşlarının farklı olması olabilir. Ayrıca, kış ölçümleri ve yaz ölçümleri karşılaştırıldığında kış ayları bizim çalışmamızda olduğu gibi yaz aylarına göre daha yüksektir. Isparta ilinde yapılan bir çalışmada, Süleyman Demirel Üniversitesinde yapılan ölçümlerde ortalama ${ }^{222} \mathrm{Rn}$ yoğunluğu $372 \pm 74 \mathrm{~Bq} \mathrm{~m}^{-3}$, şehir merkezinde bulunan bir meskende yapılan ölçümlerde ortalama $118 \pm 36$ $\mathrm{Bq} \mathrm{m}{ }^{-3}$, Yedişehitler Mahallesinde ortalama $134 \pm 41 \mathrm{~Bq} \mathrm{~m}^{-3}$, Mavikent Mahallesi $172 \pm 46 \mathrm{~Bq} \mathrm{~m}^{-3}$, Yalvaç Meslek Yüksekokulu $92 \pm 30 \mathrm{~Bq} \mathrm{~m}^{-3}$, Davraz Mahallesi $359 \pm 73 \mathrm{~Bq} \mathrm{~m}{ }^{-3}$, Halıkent Mahallesi $44 \pm 88 \mathrm{~Bq} \mathrm{~m}^{-3}$, Pri Mehmet Mahallesi $190 \pm 168 \mathrm{~Bq} \mathrm{~m}^{-3}$ ve Gökçay Mevkisi için ise $27 \pm 40 \mathrm{~Bq} \mathrm{~m}^{-3}$ olarak ölçülmüştür [44]. Isparta ilinde yapılan bu çalışmada, elde edilen sonuçlar, bizim sunduğumuz çalışma sonuçlarına göre daha yüksektir. Bunun sebebi, her iki ilin farklı jeolojik yapılar üzerinde bulunması ve inşaat malzemelerinin farklılıklarından olabilir. Bitlis ili Ahlat ilçesinde yapılan bir çalışmada, evlerde radon gazı konsantrasyon değerlerinin 10,01 ile 2031,06 $\mathrm{Bq} \mathrm{m}^{-3}$ arasında değişmekte olduğu ve ortalama değerin $259,86 \mathrm{~Bq} \mathrm{~m}^{-3}$ olduğu bildirilmiştir [45]. Sivas ilinde yapılan bir çalışmada ise bina içi radon gazı ölçümleri yaz ayları için ortalama değeri $98 \mathrm{~Bq} \mathrm{~m}^{-3}$, kış ayları için ise $89 \mathrm{~Bq} \mathrm{~m}^{-3}$ olarak ölçülmüş olup, yaz değerlerinin daha büyük çıkmasının sebebi ise bölgede yaygın olan kış mevsiminde kalın kar tabakasının erimesinden sonra zemin geçirgenliğinin artması ile ilgili olduğu bildirilmiştir [46]. İstanbul'da bir hastanede radon gazı ölçüm değerleri $19 \pm 8 \mathrm{~Bq} \mathrm{~m}^{-3}$ ile $51 \pm 15 \mathrm{~Bq} \mathrm{~m}^{-3}$ arasında olup, ortalama değerleri sırasıyla, Bodrum-1 katı için $32,5 \pm 11 \mathrm{~Bq} \mathrm{~m}^{-3}$ ve Bodrum-2 katı için 31,6 $\pm 10 \mathrm{~Bq} \mathrm{~m}^{-3}$ bulunmuştur [47]. Ayrıca Polonya'da yapılan bir çalışmada ise üç farklı hastanede ölçülen radon konsantrasyonu ortalama değerleri, bodrum kat için $25,3 \mathrm{~Bq} \mathrm{~m}^{-3}, 45,5 \mathrm{~Bq} \mathrm{~m}^{-3}$ ve $32,3 \mathrm{~Bq} \mathrm{~m}^{-3}$, zemin kat için ise $19,7 \mathrm{~Bq} \mathrm{~m}^{-3}, 24,9 \mathrm{~Bq} \mathrm{~m}^{-3}$ ve $18,6 \mathrm{~Bq} \mathrm{~m}^{-3}$ olarak ölçülmüştür [48]. Hem İstanbul'da hem de Polonya'da yapılan çalışma sonuçları ile sunduğumuz bu çalışma sonuçları uyum içerisindedir.

\section{Sonuç ve Öneriler}

Kapalı mekânlarda radon gazı oranı binanın temelindeki toprak ve kayalardan kaynaklanmaktadır. Sabah erken saatlerde günlük radon konsantrasyonları en yüksek değerde olma eğilimindedir. Kapalı ortam sıcaklığı da havadan ağır olan radon gazının yükselmesine ve daha büyük bir hacim kaplamasına neden olur. 
Yaptığımız ölçümlerde, yaz mevsimi ölçümlerinin düşük çıkmasının başka bir nedeni ise, havalandırma olup yaz aylarında kapı ve pencerelerin açık olması ile havalandırma sürekli ve günlük yapılırken kış aylarında dış ortamın soğuk olması nedeniyle havalandırmanın yapılmamasından olabilir. Sonuçlar beklenilen değerlerle uyuşmaktadır. Bu durumda çalışma ortamlarının ve binaların özellikle kış aylarında da havalandırılması tarafımca önerilmektedir.

Ölçümler sonrası elde edilen değerler, insan sağlığı için ICRP, WHO, AB ve TAEK tarafından önerilen seviyelerle karşılaştırma yapıldığında, önerilen değerleri aşmadığı görüldü. TAEK' in belirlediği maksimum müsaade edilen radon gazı konsantrasyon limitine (evlerde $400 \mathrm{~Bq} \mathrm{~m}^{-3}$, iş yerlerinde ise $1000 \mathrm{~Bq} \mathrm{~m}^{-3}$ ) göre değerlendirildiğinde, genelde ortalama yıllık $30-350 \mathrm{~Bq} \mathrm{~m}^{-3}$ arasında değişmektedir. Bu ölçüm değerleri bize, KSÜ Avşar Yerleşkesi'nde bulunan fakülte ve idari birimlerden oluşan toplam 12 binanın, radon gazı ve onun kısa yarı ömürlü kız çekirdeklerinin oluşturabileceği sağlık riskleri bakımından önemli bir tehlike taşımadığını göstermektedir.

Hayatımızın kaçınılmazı doğal radyasyon her yerde vardır. Burada önemli olan ise radyasyona maruz kalma dozunu azaltmaktır. Binalar yapılırken, binanın oturacağı zemininin radon gazı sızıntıları için yalıtılması, bina içi radon gazı konsantrasyonunun oldukça düşük olmasını sağlayabilir. Ayrıca yukarıda da önerdiğim gibi kapalı mekânların özellikle kış aylarında havalandırılması, radon gazı konsantrasyonunun azaltılmasında büyük bir rol oynamaktadır. Bina içi havalandırma yapılırken izolasyonu yüksek binaların havalandırma sürelerinin uzun tutulmasını da öneririm. Havalandırmanın önemini UNSCEAR ve ICRP'de vurgulamaktadır. Ayrıca bu tür ölçümlerin her yıl yapılması çalışanlar ve öğrencilerin sağlığı açısından da önemlidir.

\section{Teșekkür}

$\mathrm{Bu}$ çalışma, KSÜ BAP birimi tarafindan desteklenmiştir. Proje No: 2014/4-34M. KSÜ Bilimsel Araştırma Projeleri Yönetim Birimine teşekkür ederim.

\section{Yazarların Katkısı}

Çalışmada tüm katkı yazara aittir.

\section{Çıkar Çatışması Beyanı}

Yazarlar arasında herhangi bir çıkar çatışması bulunmamaktadır.

\section{Araştırma ve Yayın Etiği Beyanı}

Yapılan çalışmada araştırma ve yayın etiğine uyulmuştur.

\section{Kaynaklar}

[1] Gillmore G.K., Phillips P.S., Denman A.R., Gilbertson D.D. 2002. Radon in the Creswell Crags Permian limestone caves. Journal of Environmental Radioactivity, 62 (2): 165- 179.

[2] Sandıkçıŏlu A. 2004. Afyon Deprem Fay Hattı Üzerinde Bulunan Kaplıca ve Kuyu Sularındaki Radon Değişiminin Ölçümü. Yüksek Lisans Tezi, Anadolu Üniversitesi, Fen Bilimleri Enstitüsü, Eskişehir, 1-112.

[3] Kuluöztürk M.F., Büyüksaraç A., Özbey F., Yalçın S. 2017. Determination of radon gas activity levels in drinking water in Ahlat/Bitlis. Bitlis Eren University, Journal of Science and Technology, 7(2): 104-107.

[4] Uyanık N.A., Akkurt I., Uyanık O. 2010. A ground radiometric study of uranium, thorium and potassium in Isparta, Turkey. Ann. of Geophys, 53: 25-30.

[5] Mavi B., Akkurt I. 2010. Natural radioactivity and radiation hazards in some building materials used in Isparta. Turkey. Rad. Phys. Chem., 79 (9): 933-937.

[6] Aközcan S. 2014. Annual effective dose of naturally occurring radionuclides in soil and sediment. Toxicologycal and Environmental Chemistry, 96 (3): 379-386. 
[7] Akkurt I., Uyanık N.A., Günoğlu K. 2015. Radiation Dose Estimation: An In Vitro Measurement For Isparta-Turkey. International Journal of Computational and Experimental Science and Engineering, 1 (1): 1-4.

[8] Çetin B., Öner F., Akkurt I. 2016. Determination of Natural Radioactivityand Associated Radiological Hazard in Excavation Field in Turkey (Oluz Höyük). Acta Physica Polonıca A, 130 (1): 475-478.

[9] Seçkiner S., Akkurt I., Günoglu K. 2017. Determination of 40K concentration in gravel samples from Konyaaltı Beach, Antalya. Acta Physica Polonıca A, 132 (3-II): 1095-1097.

[10] Günay O., Aközcan S., Kulalı F. 2018. Bina İçi Radon Konsantrasyonlarının Belirlenmesi. Avrupa Bilim ve Teknoloji Dergisi, 13: 91-97.

[11] Durrani A.S., Ilic R. 1997. Radon Measurements by Etched Track Detectors: Applications in Radiation. Earth Sciences and Enviroment. World Scientific Publishing Co. Pte. Ltd, England, 416 sayfa.

[12] Sarı S., Dizman S. 2020. Ovit Dağbaşı Gölü Çevresinden Alınan Toprak Örneklerinde Radyoaktivite ve Radyolojik Etkilerin Araştırılması. El-Cezerî Fen ve Mühendislik Dergisi, 7 (3): 1122-1130.

[13] UNSCEAR. 1998. United Nations Scientific Committe on the Effects of Atomic Radiation; Sources, Effects, and Risks of Ionizing Radiation. United Nations sales publication, No:E.88.IX.7.New York.

[14] Vural S.M. 2004. Yapı İçi Hava Niteliği Risk Süreci Modeli Belirlenmesi. Yüksek Lisans Tezi, Yıldız Teknik Üniversitesi, Fen Bilimleri Enstitüsü, İstanbul, 1-100.

[15] Değerlier M. 2007. Adana İli ve Çevresinin Çevresel Doğal Radyoaktivitesinin Saptanması ve Doğal Radyasyonların Yıllık Etkin Doz Eşdeğerinin Bulunması. Doktora Tezi, Çukurova Üniversitesi, Fen Bilimleri Enstitüsü, Adana, 1-175.

[16] Selçuk A.B. 1996. Elazığ Yöresindeki Evlerde Radon Gazı Ölçümü. Yüksek Lisans Tezi, Fırat Üniversitesi, Fen Bilimleri Enstitüsü, Elazığ, 1-78.

[17] Espinosa G., Golzarri J.I., Martinez T., Navarette M., Boggard J., Martinez G. 1996. Indoor ${ }^{220}$ Rn and ${ }^{222} \mathrm{Rn}$ Concentration Mesurements Inside The Teotihuacan Pyramids Using NTD and EPERM Methodoligies. Radiation Measurements, 40: 646-649.

[18] Planiniç J., Faj D., Vukoviç B., Faj Z., Radoliç V., Suveljak B. 2002. Radon exposure and lung cancer. Journal of Radioanalytical and Nuclear Chemistry, 256: 349-352.

[19] Kapdan E. 2009. Adapazarı Merkezi Kış Dönemi Radon Ölçüm ve Analizleri. İstanbul Teknik Üniversitesi, Enerji Enstitüsü, İstanbul, 1-91.

[20] Çıtlak K. 2018. Sakarya Üniversitesi Kampüs Bölgesinde Bina İçi Radon Konsantrasyonunun Belirlenmesi. Yüksek Lisans Tezi, Sakarya Üniversitesi, Fen Bilimleri Enstitüsü, Fizik Anabilim Dal, Sakarya, 1-69.

[21] Çelebi N. 1995. Çevresel Örneklerde Uranyum, Radyum ve Radon Ölçüm Tekniklerinin Geliştirilmesi. Doktora Tezi, İstanbul Üniversitesi, Fizik Anabilim Dalı, İstanbul, 1-83.

[22] Kumbur H., Zeren O., Köksal M., Özçınar B. 1997. İçel'de Evlerde Radon Düzeylerinin Araştırılması. Ekoloji Çevre Dergisi, 25 (7): 25-31.

[23] Çelebi N., Taşdelen M., Özçınar B., Kopuz G. 2003. YTÜ Şevket Sabancı Kütüphanesi Radon Konsantrasyon Ölçümleri. VII. Ulusal Nükleer Bilimler ve Teknolojileri Kongresi, 15- 17 Ekim, Kayseri.

[24] Fişne A., Otken G., Çelebi N. 2005. Radon Concentration Measurements in Bituminous Coal Mines. Radiation Protection Dosimetry, 113 (2): 173-177.

[25] Baldık R., Aytekin H., Çelebi N., Ataksor B., Taşdelen M. 2006. Radon Concentration Measurements in the Amasra Coal Mine, Turkey. Radiation Protection Dosimetry, 118 (1): 122 125.

[26] Yarar Y., Günaydı T., Çelebi N. 2006. Determination of Radon Concentrarations of the Dikili Geothermal Area in Western Turkey. Radiation Protection Dosimetry, 118 (1): 78-81.

[27] Aytekin H., Baldık R., Çelebi N., Ataksor B., Taşdelen M, Kopuz G. 2006. Radon Measurements in the Caves of Zonguldak (Turkey). Radiation Protection Dosimetry, 118 (1): 117-122.

[28] Değerlier M., Çelebi N. 2008. Indoor Radon Concentrations in Adana, Turkey. Radiation Protection Dosimetry, 131 (2): 259-264 
[29] Aytekin H., Bayata S., Baldık R., Çelebi N. 2008. Radon Measurement in the Çatalağzı Thermal Power Plant, Turkey. Radiation Protection Dosimetry, 128 (2): 251-253.

[30] Baldık R., Aytekin H., Çelebi N. 2009. Radon Fluctuations in the Armutçuk Coal Mine, Turkey. Fresenius Environmental Bulletion, 18 (1): 87-91.

[31] Karakılıç V., Bayraktar G., Kürkçüoğlu M.E., Haner B., Yılmaz A. 2009. S.D.Ü. Bilgi Merkezi'nde Radon Ölçümleri. Süleyman Demirel University Journal of Natural and Applied Sciences, 13 (3): 201-207.

[32] Kürkçüoğlu M.E., Bayraktar G. 2012. Süleyman Demirel Üniversitesi’nde Bina İçi Radon Konsantrasyonlarının Nükleer İz Dedektörleri Kullanılarak Belirlenmesi. Süleyman Demirel Üniversitesi Fen Bilimleri Enstitüsü Dergisi, 16 (2): 167-183.

[33] Kürkçüoğlu M.E., Haner B., Yılmaz A., Toroğlu İ. 2009. Karaelmas Yerleşkesi Merkez Kütüphanesi Radon Ölçümleri. SDÜ Fen Edebiyat Fakültesi Fen Dergisi, 4 (2): 177-188.

[34] George A.C. 2007. World History of Radon Research and Measurement from the Early 1900's to Today. http://www.crcpd.org/radon/Radon_Bulletin/Nov ember07RB.pdf (Erişim tarihi: 29.03.2009).

[35] ICRP Publication 50. 1987. Lung cancer risk from indoor exposure to radon daughters. Annals of the ICRP, 17: 1-60.

[36] Avşar Y. 2015. Kahramanmaraş il merkezindeki bazı ilköğretim ve anaokullarında radon gazı ölçümü. Yüksek Lisans Tezi, Kahramanmaraş Sütçü İmam Üniversitesi, Fen Bilimleri Enstitüsü, Kahramanmaraş, 1-98.

[37] Kop A. 2010. Faylarla ilişkili jeotermal alanlarda radon gazı ölçümlerinin önemine ilişkin bir örnek, Hartlap kaplıcası, Kahramanmaraş. İstanbul Yerbilimleri Dergisi, 23 (1): 39-52.

[38] http://www.turkiyerehberi.gen.tr/sehirler/book/export/html/192.

[39] ICRP Publication 65. 1993. Protection Against Rn-222 at Home and at Work. Annals of the ICRP, 23 (2).

[40] Sannappa J., Chandrashekara M.S., Sathish L.A., Paramesh L., Venkataramaiah P. 2003. Study of background radiation dose in Mysore city. Karnataka State. India. Radiation Measurements, 37 (1): 55-65.

[41] Akyıldırım H. 2005. Isparta İli’nde Radon Yoğunluğunun Ölçülmesi ve Haritalandırılmas1. Yüksek Lisans Tezi, Süleyman Demirel Üniversitesi, Fen Bilimleri Enstitüsü, Isparta.

[42] NCRP. 1988. Measurements of Radon and Radon Daughters in Air. Report, 97, p174.

[43] Kürkçüoğlu M.E., Tozun F. 2015. Isparta İl Merkezindeki İş Yerlerinde Atmosferik Radon Ölçümleri. SDU Journal of Science (E-Journal), 10 (1): 62-74.

[44] Özkorcuklu S., Akyıldırım H., Çapalı V. 2006. Isparta İli’nde Radon Yoğunluk Ölçümleri. Süleyman Demirel Üniversitesi, Fen Bilimleri Enstitüsü Dergisi, 10 (3): 323-327.

[45] Kuluöztürk M.F., Büyüksaraç A., Özbey F., Yalçın S., Doğru M. 2019. Determination of indoor radon gas levels in some buildings constructed with Ahlat stone in Ahlat/Bitlis. International Journal of Environmental Science and Technology, 16: 5033-5038.

[46] Mihcı M., Büyüksaraç A., Aydemir A., Çelebi N. 2010. Indoor and outdoor Radon concentration measurements in Sivas, Turkey, in comparison with geological setting. Journal of Environmental Radioactivity, 101: 952-957.

[47] Günay O., Aközcan S., Kulalı F. 2018. Bina İçi Radon Konsantrasyonlarının Belirlenmesi. Avrupa Bilim ve Teknoloji Dergisi, 13: 91-97.

[48] Mnich Z., Karpinska M., Kapala J., Kozak K., Mazur J., Birula A., Antonowicz K. 2004. Radon concentration in hospital buildings erected during the last 40 years in Białystok. Poland Journal of Environmental Radioactivity, 75 (2): 225-232. 